\title{
Microeconomic framework for the economics of whales
}

\author{
Laura Onofri ${ }^{1, *}$, Paulo A. L. D. Nunes ${ }^{2}$ \\ ${ }^{1}$ Department of Land, Environment, Agriculture and Forestry, University of Padua, 35122 Padua, Italy \\ ${ }^{2}$ Ecosystem Services Economics Unit, Division of Environmental Policy Implementation, United Nations Environment \\ Programme (UNEP), PO Box 30522, United Nations Avenue, 00100 Nairobi, Kenya
}

\begin{abstract}
We adopted an economic analysis to evaluate and discuss the management of conservation and commercial exploitation of whales. In particular, the paper starts from the recent proposal to create and implement a quota market for whale trading and attempts to address and develop selected economic issues, in order to move towards understanding the economics of whales. We can summarize our findings in 2 main points: (1) the choice of the quota pre-trade value, number and allocation criteria will have different impacts on the way trade will occur; (2) the definition of the rules of trade and the study of the market structure where trade occurs will also determine the final outcome. From this perspective, quota markets for whales will support conservation and discourage whaling only under stringent conditions and careful monitoring, the costs of which need to be carefully valued and distributed among stakeholders according to agreed criteria.
\end{abstract}

KEY WORDS: Marine natural resources · Economic value · Trade · Quota system · Market structure · Perfect competition · Monopsony $\cdot$ Impure public good $\cdot$ Public policy

\section{INTRODUCTION}

The economics and management of whales, which include highly migratory species recognized in Annex I of the United Nations Convention on the Law of the Sea, have captured the attention of economists for several reasons. On the one hand, whales contribute to the provision of a wide range of benefits to humans. First, aboriginal subsistence whaling constitutes a major nutritional contribution to the livelihoods of remote communities (e.g. western Greenland, see the website of the International Whaling Commission, IWC, at http://iwc.int/data-availability). Second, whales provide benefits derived from whale watching and recreational activities all over the world. Third, whales have a number of important biological characteristics that contribute to their capacity to influence the habitats where they live, contributing, among other functions, to the regula- tion of the nutrient flow and fertilization of marine waters (Ghermandi \& Nunes 2013). Many interpret the influence of these marine mammals on marine ecosystems as that of 'ecosystem engineers', taking into consideration their interaction with and influence on their physical habitats. Finally, whales vividly populate our imaginary and historic-cultural landscapes, representing a common, worldwide heritage asset. On the other hand, unregulated whaling has contributed, and still contributes, to unprecedented rates of loss in the global population of whales, threatening the stability and continuity of ocean ecosystems as well as their provision of goods and services to humans.

This situation has prompted many experts and researchers to propose viable and practical solutions for the sustainable management of whaling activities. Among which is the International Whaling Commission (IWC). However, neither IWC actions, includ- 
ing its Moratorium on Commercial Whaling (beginning in 1986), nor actions taken by non-governmental agencies (e.g. World Wide Fund for Nature [WWF], Greenpeace, Sea Shepherd Conservation Society) and the scientific community have completely stopped or eradicated whale hunting.

In this context, here we explore an economic analysis to discuss the management of conservation and commercial exploitation of whales. In particular, we begin with a study by Costello et al. (2012), who proposed a quota market for whale trading, and we attempt to address and develop some issues by making use of a microeconomic framework in order to move towards understanding the economics of whales.

The paper is organized as follows. Below we discuss selected statistics on whaling activities and whale populations. In the subsequent section, we present a microeconomic analysis of the quota system, including quota allocation, implementation and economic value. In the last section, we discuss the analysis from a critical perspective and conclude the paper.

\section{WHALING COUNTRIES AND WHALES: EMPIRICAL EVIDENCE AND STYLIZED FACTS}

In this section, we provide some empirical figures and stylized facts (see Appendix for definition) on whaling countries and whales. Good conservation and management of whales require an understanding of the status of their populations. A key component of this is an estimate of present abundance (and ideally trends in abundance) against which possible threats can be evaluated. It is very difficult to find data and/or estimates on whale populations worldwide. It is also very difficult to find a consensus on those figures. Different sources are available, and various attempts have been made to estimate whale populations. A major effort can be traced in the work by Schipper et al. (2008), who highlighted that our knowledge of mammalian diversity is still surprisingly disparate, both regionally and taxonomically. They presented a comprehensive assessment of the conservation status and distribution of the world's mammals, using data compiled by $>1700$ experts and covering all 5487 known species, including marine mammals. Different compilations of data are also available according to different 'political' and economic sources of the data themselves. For this reason, we selected the IWC data as a 'super partes' (i.e. impartial) institution.
From the IWC data (https://iwc.int/estimate\#table), we highlight 3 main pieces of information: (1) a census of different species of whales and their population trends; (2) the main commercial whaling countries; (3) countries in which whaling is conducted for aboriginal subsistence. Catches taken under objection from the IWC in the period 1986 to 2012 (mostly minke whales, but also a small percentage of fin and Bryde's whales) are mostly attributed to Norway (10106 pieces), Japan (5529) and Iceland (251) (https://iwc.int/table_objection).

Aboriginal subsistence whaling catches in the period 1985 to 2012 were by Denmark (Eastern and Western Greenland region; 4597 pieces), St. Vincent and the Grenadines (29 pieces), Russia (3158 pieces) and the US (1256 pieces). The most commonly harvested species were minke, bowhead and grey whales (https://iwc.int/table_aboriginal).

We can summarize the evidence as follows: first, commercial whaling countries are mostly Japan, Norway and Iceland (with both Japan and Iceland bound by the IWC moratoria); second, some subsistence whaling is allowed by the IWC; and third, there are different cases (based on IWC estimates) that signal small increases in population sizes (i.e. fin whales in the period 1995 to 2001 in the regions of East Greenland and the Faroes) or significant decreases in numbers (e.g. minke whales in the period 1996 to 2007 in the northeastern region of the Atlantic Ocean).

\section{QUOTA SYSTEM FOR WHALES}

To our knowledge, the use of economic thinking and methods to address the issue of whale conservation and management dates back to Clark (1973), who argued that, with a sufficiently high interest rate and a species with slow population growth, such as the blue whale, it may be economically profitable to hunt it to extinction. Blue whale populations, in fact, are very slow growing. Scientists have estimated that blue whales have a maximum reproductive potential of perhaps 4 to $5 \%$ per year, a rate lower than the interest rate that other investments can pay. As a result, conservation of this species is not economically viable, and a quick harvesting and re-investment of the profits in more profitable sectors is advisable in strictly (neoclassical) economics terms. Therefore, given at least a much higher expected return on capital, protecting these whales makes no economic sense.

Costello et al. (2012) adopted economic theory in order to suggest a conservation strategy based on an 
open quota market for living whales, which could represent a regulatory mechanism for conservation, since quota allocation and trade will both limit and regulate the whale supply. The authors proposed to create a quota market and let those with the highest willingness to pay for the whales purchase more quotas from the world market.

Smith et al. (2014) critiqued the proposal of Costello et al. (2012), by highlighting that whales are impure public goods from the perspective of economic theory (see Appendix). Therefore, an economic policy instrument (see Appendix) that fails to capture all non-market benefits (due to free riding, see Appendix) could lead to a suboptimal outcome. Even if free riding were overcome, whale shares would face several implementation challenges, spanning from potential expansion of the international market of whale meat to management, monitoring and enforcement challenges, as well as the problem of definitions of quota number, and value and allocation mechanisms.

In this section, using an economic framework, we consider the quota system with a 2-fold perspective. We look at 2 important stages of the quota system proposal. First we investigate different pre-trade valuation and allocation mechanisms of the quota. Second, we analyse the trade organization and market structure where the quota should be traded.

An important methodological caveat needs to be stressed. Our approach is highly pragmatic and evidence based. At the moment, there are several subsistence whaling countries and 3 main commercial whaling countries, 1 of which is highly committed for both cultural and commercial purposes. Whales are also inputs to the whale-watching business worldwide, as a particular segment of the tourism sector. In addition, there are several non-governmental organizations (NGOs) and environmental associations worldwide attempting to protect and conserve whales. In technical terms, the revealed preferences (see Appendix) for whales (for the purposes of both conservation and commercial use) are well defined and clearly identifiable when considering the status quo, as delimited by actual evidence. Our starting point is therefore that the quota proposal is framed (unless there are future huge investments in information, advocacy or education campaigns, which still imply opportunity costs) for limited stakeholders. The potential willingness to pay for quotas implies opportunity costs (see Appendix), in a context of scarce resources, as belonging by definition to economic analysis ${ }^{1}$. Governments and stakeholders face budget constraints and, therefore, opportunity costs in choices. Such crucial considerations frame the rest of the analysis.

\section{Pre-trade phase: creating, valuing and allocating the quota}

A crucial unanswered point in the study by Costello et al. (2012) refers to the modality of the (pre-trade) definition of the number and value of the quotas and their allocation. There are different methods and approaches to address those points. For instance, a method can be based on the value produced by whales in the sectors where they are input to production. In this case, different economic values, based on the economic productivity of whales, can be computed. Whales are input to the whale watchingmarket, to the whale meat market and to other activities linked to the food industry, among the others. Another approach can be strictly biophysical and can be based on the (estimated) number of whales (with the idea that 1 whale equals 1 quota) or on the biological productivity of whales. The actual stock remains untouched and only newborn whales can enter the quota market. In addition, in the quota definition and allocation, the geographical location of whales and how many are harvested in each period would matter. The definition and allocation criteria can be different and follow different approaches that are explored in the following.

\section{Legal approach}

Suppose we follow a strictly legal approach and allocate quotas according the Common Heritage of Mankind, a principle of international law, which holds that defined territorial areas and elements of humanity's common heritage (cultural and natural) should be held in trust for future generations and be protected from exploitation by individual nation

1 Governments face investments for schooling, education, health, public defence and nature conservation, as do individuals, committed to living, housing and many other investments. Paying for the whale quota generates an opportunity cost. A real preference for a good, in economics, is manifested by the revealed preference, e.g. the exchange/purchase in the market. When a market for the good does not exist, economic methodology allows the technician to 'recreate' market conditions and elicit 'stated preferences'. However, those techniques are prone to criticism since preferences are only stated, i.e. they are potentials, and actual market exchange has not occurred 
states or corporations. According to this legal criterion, whales (and the entire stock of them) belong to all of mankind ${ }^{2}$. Therefore, we can assume that the whale quota per person, $\mathrm{Q}_{\mathrm{PP}}$, in the world equals:

$$
\mathrm{Q}_{\mathrm{PP}}=\frac{\mathrm{T}_{\mathrm{W}}}{7 \times 10^{9}}
$$

where $T_{W}$ is the total number of whales in the oceans and the denominator is the total number of people on earth. For the sake of simplicity, we estimate that there are around 1.4 million whales in the seas (sum of IWC data). This implies that every person owns a quota of 0.0002 whales.

If the quota can be traded, it is crucial to determine the value of the quota in monetary terms. Following the legal criterion, the value of the quota, $V_{\mathrm{Q}}$ owned by each person equals:

$$
\mathrm{V}_{\mathrm{Q}}=\frac{X}{7 \times 10^{9}}
$$

where $X$ is the economic value of the whales (to be determined, see below) and the denominator is the number of people on earth. Adopting a strictly market approach (disregarding any non-market consideration) and taking the average of the 2 extreme perwhale proft values suggested by Costello et al. (2012) of ca. US\$13000 (minke whale) and US\$85000 (fin whale), we can assume the market value of a whale equals ca. US\$49000. The total market value of the whales (and related quota market) is the average market price (value) of a whale multiplied by the estimated stock of whales and equals US\$68 600 000. In addition, citing Costello et al. (2012, p. 140): 'A conservative estimate of the amount spent annually by non-profit organizations on anti-whaling (based on the expenditures of Greenpeace USA, Greenpeace International, Sea Shepherd Conservation Society, WWF International and WWF UK) is \$25 million'. The latter value can be interpreted as a 'non-market value' that embodies and evaluates the non-use value, including bequest and existence values. In addition, a recent estimate by $\mathrm{O}^{\prime}$ Connor et al. (2009) on the value of the whale-watching sector indicates that it generates an annual revenue of $\$ 2.1$ billion.

2If we recognize that whales belong to mankind, from an economic perspective, we can interpret the legal principle in 2 ways, either as an allocation of property rights on the whales to humans, or considering whales as public goods, i.e. those particular goods that are characterized by 2 main features: (1) non-excludability in consumption; (2) non-rival in consumption. Under this scenario, the governance structure must be 'regulatory'. The IWC (or any other institution) must regulate and control the resource
Summing up the estimated non-market value to the estimated market values of whales, we can calculate the value of $X$ as US\$2 $193600000^{3}$. In accordance with Eq. (2), the value of each quota equals US\$0.313. Under this scenario, every human willing to pay 31.3 cents of a dollar (or more) can purchase a quota of whales from those individuals who are willing to receive at least 31.3 cents of a dollar for selling their share of a whale.

\section{Economic theory-based approach}

Suppose we follow an economic theory-based approach. Economics provides several theories and methods for the definition of value, even though the attribution of the economic value to resources, goods and services is still a debated issue among economists. In particular, the real capabilities of market prices to signal and measure the scarcity of resources/goods and services is achieved only under very stringent conditions (e.g. perfect competition, perfect information). At the same time, non-market valuation methods are severely scrutinized since they are often based on methodological constructions that mimic market dynamics in contexts where markets do not exist. In this context, we focus our attention on a few selected approaches.

First, suppose that the economic value is strictly defined by the capability of the resource to produce profits, as in the scenario proposed by Clark (1973). In this case, a definition criterion of the economic value of the single quota can be traced in the concept of marginal revenue or marginal profit (the marginal revenue can also be interpreted as the economic value of the marginal product of whales). The quota should be valued, in monetary terms, as the additional revenue produced by the use of the additional whale in the selected economic sector (or the additional revenue minus the additional costs):

$$
\mathrm{V}_{\mathrm{Q}}=\mathrm{MR}=\frac{\partial \mathrm{T}_{\mathrm{R}}}{\partial \mathrm{Q}_{\mathrm{W}}}
$$

where MR is marginal revenues (see Appendix), $T_{R}$ is total revenues (a measure for the producers' surplus)

\footnotetext{
3It is possible that a conservationist is also recorded as a whale watcher in our data. This means that the individual has expressed his preference and related willingness to pay for the whales, both as a conservationist and as a whale watcher. This operation does not qualify as double counting, but as a disentangling of total willingness to pay in the market and non-market dimensions
} 
and $Q_{W}$ is the amount of whales used in the sector. Although such a value is easily computed for the whaling sector (for instance, it equals US\$13 000 for a minke whale and US\$85000 for a fin whale, as reported by Costello et al. 2012), it is very difficult to compute for the whale-watching sector, where only 1 whale, observed in the open sea, can be the source of revenues for a whole boat tour. A proxy indicator can be provided by the expenditures of whale-watchers in the sector. A recent estimate by Cisneros-Montemayor et al. (2010) reported an amount of US\$179 per capita worldwide. In this case, therefore, the marginal revenue produced by the very same resource can be US\$13 000 (in the whaling market) or US\$179 in the whale-watching sector. One of the 2 monetary values can represent the value of the quota. In this case, the whaler would be willing to sell each quota only for a value equal to or higher than US\$13000 dollar, whereas the whale-watching firm would probably be willing to sell each quota for a value equal to or higher than US\$179. From the initial attribution of value follows the definition of the number of quotas. The number of quotas will probably be higher if the selected value of a single quota is the marginal revenue in the whaling sector and lower otherwise. This depends on the concept of scarcity of natural resources. From the valuation approach we can also derive the initial allocation of quotas. It might be straightforward to allocate quotas to those who produce revenues from whales and design a regulatory mechanism that forces them to trade. However, quotas could be distributed to all potentially interested stakeholders and not exclusively to operators in whaling and whale-watching markets. Both scenarios would minimize rent extraction, i.e. an activity aiming at increasing one's share of existing wealth without creating wealth.

Second, an alternative economic theory-based approach is welfare oriented and takes into consideration the public good features of the whales (as highlighted by Smith et al. 2014). In this perspective, markets fail to price and value the resource. Therefore, in order to correctly attribute a value to the whales, the policy-maker should look at the total welfare generated by the whales and define the quota number and monetary value using criteria based on either equity or efficiency. By a priori neglecting any public choice theory implications, such an approach assumes the capability of the policy maker, as a benevolent dictator, to achieve those allocations and equilibria that the market failed to achieve. As an example, if we assume a utilitarian welfare function (where total welfare is derived as the sum of consumer and producer surplus), we can define the total welfare function as Total Welfare $=$ Consumer Surplus + Producer Surplus. Consumer surplus is represented by the NGOs' willingness to pay for whales. Producer surplus is the revenue of whalers and whale-watching firms. In this case, the value of the quota can be defined as:

$$
\mathrm{V}_{\mathrm{Q}}=\frac{\partial \text { Total Welfare }}{\partial \mathrm{Q}_{\mathrm{W}}}
$$

In this case, the value of the quota is interpreted as the value society attributes to whales, in the complex multifaceted dimensions and uses. With the available data, the value of the quota is around US\$1566.

Finally, in the most neoclassical framework, the number of the quotas and their value (expressed in monetary terms) can be established by the policy makers under consideration of the positive externalities generated by the whales. In this perspective, the value of the quota (and related number) results in a 'symbolic' price, such as in the case of entry fees in public museums, since the beneficial effects of whales on society would require the maximum possible 'consumption' at the minimum price. Such an approach supports the conservationist vision of the whales, but would confer a cheap 'licence to kill' to whalers.

\section{Biophysical approach}

Suppose that the value of quotas is determined following a biophysical approach. In this case, the quota should be defined by taking into account the ecological and ecosystem services provided by the whales and/or the productivity of the animals (e.g. the number of newborns per whale per year) derived by ecological production functions. In addition, a biophysical approach should take into consideration the migratory characteristics of the whales and the related difficulties to attach property rights to those resources. In this scenario, an ad hoc institution, for instance, the IWC, may establish on an annual basis the total number of whales that can be caught. That number would represent the total annual quotas. In such a way, the resource is not depleted and the whaling countries can continue their traditions. The monetary value of the quota, however, is more difficult to determine by following a strict biophysical criterion. In this case, for instance, the value can be determined by auctions. Following auction theory, auction participants will pay that price (per available unit of whales) that 
equals their real reservation price (and therefore, willingness to pay) that embodies both market and non-market values (if any). In this case, as mentioned by Costello et al. (2012), whaling countries, 'greens', non-profit organizations and any kind of stakeholders can participate in the auction and buy biophysically pre-defined quotas. The reservation price and the competition among the auction participants will determine the quota economic value. The auction organizing institution can decide a 'minimum' price based on clear criteria. Table 1 summarizes the main points of this pre-trade phase.

\section{Trade phase: organization and market structure}

Assuming that a criterion for the definition, allocation and valuation of quotas has been defined and implemented, the next step refers to the analysis of quota trading. Quota trading implies 2 dimensions of analysis: (1) the organization of trade and/or the definition of the rules that govern trade and (2) the study of the market structure where trade occurs.

\section{Organization of trade}

We consider 2 types of trade organization: (1) free market and (2) a regulated system. The different equilibria are summarized in Fig. 1, which shows 2 different equilibria related to different organizations of trade (and pricing) in a whale quota market. In the graph, the $y$-axis maps the price of quotas and the $x$ axis maps the quantity of quotas.
Free market dynamics. Let us first assume that the trade procedure will follow free market dynamics. Suppose that the number and value of the quota have been defined and allocated and that stakeholders can trade following free market dynamics. In Fig. 1 we graph selected equilibria achieved by the 2 considered trade procedures. Suppose that every country that wants to participate in the trade of quotas is allocated $\mathrm{Q}_{\mathrm{K}}$ initial amount of quotas at price $\mathrm{P}_{\mathrm{K}}$ (both established by any of the approaches discussed in the previous section and not graphed). The free market equilibrium is described by point $\mathrm{H}$. The triangle $\mathrm{K}$ $\mathrm{H}-\mathrm{Z}$ graphs the 'purchasing space', every country's willingness to buy an incremental number of quotas at corresponding prices. At the same time, every country participating in the trade can sell the initial quota endowment up to the point where it has no more quotas to sell. The triangle $\mathrm{K}-\mathrm{P}_{\text {quota }}-\mathrm{P}_{\text {price }}$ graphs the 'selling space' and every country's willingness to sell an incremental number of quotas at corresponding prices. The marginal cost function can vary across different stakeholders since it depends on the available budget and on potential aid received by the buyer (i.e. donors for NGO's or subsidies for whaling countries). Obviously, the lower the marginal costs are, the higher is the amount of quotas that can be purchased, and vice versa.

Regulated system. Now assume that an authority (for instance the IWC) regulates quota trade (for the purpose of sustainability of whale populations, or for strategically discouraging trade and/or for creating scarcity rents). The authority can fix minimum and maximum trade caps as graphed in Fig. 1, where trade can occur only between $\mathrm{Q}_{\mathrm{A}}$ and $\mathrm{Q}_{\mathrm{B}}$. The area of

Table 1. Different criteria to define quota numbers and values (expressed in monetary terms) for activities related to whaling and whale-watching. An in-depth discussion is provided in the main text in the section 'Pre-trade phase: creating, valuing and allocating the quota'. NA: not applicable

\begin{tabular}{|c|c|c|c|}
\hline & Legal & Economic & Biophysical \\
\hline Quota & $\begin{array}{l}\text { Total number of whales / } \\
\text { total number of people } \\
\text { on Earth }\end{array}$ & $\begin{array}{l}\text { Dependent on the selected } \\
\text { economic valuation approach }\end{array}$ & $\begin{array}{l}\text { 1. Biophysical productivity of whales } \\
\text { / ecological production functions } \\
\text { 2. Total number of whales }\end{array}$ \\
\hline Quota value & $\begin{array}{l}\text { Total value of whales / } \\
\text { total number of people } \\
\text { on Earth }\end{array}$ & $\begin{array}{l}\text { 1. Marginal revenue / } \\
\text { economic value of the marginal } \\
\text { productivity } \\
\text { 2. Marginal social welfare } \\
\text { 3. Positive externality (Appendix) } \\
\text { generated by symbolic value }\end{array}$ & Bidders' reservation price in auctions \\
\hline 2010 US\$ & 0.31 & $\begin{array}{l}\text { 1. } 49000 \text { (for whaling); } \\
179 \text { (for whale watching) } \\
\text { 2. } 1566 \\
\text { 3. NA }\end{array}$ & NA \\
\hline
\end{tabular}




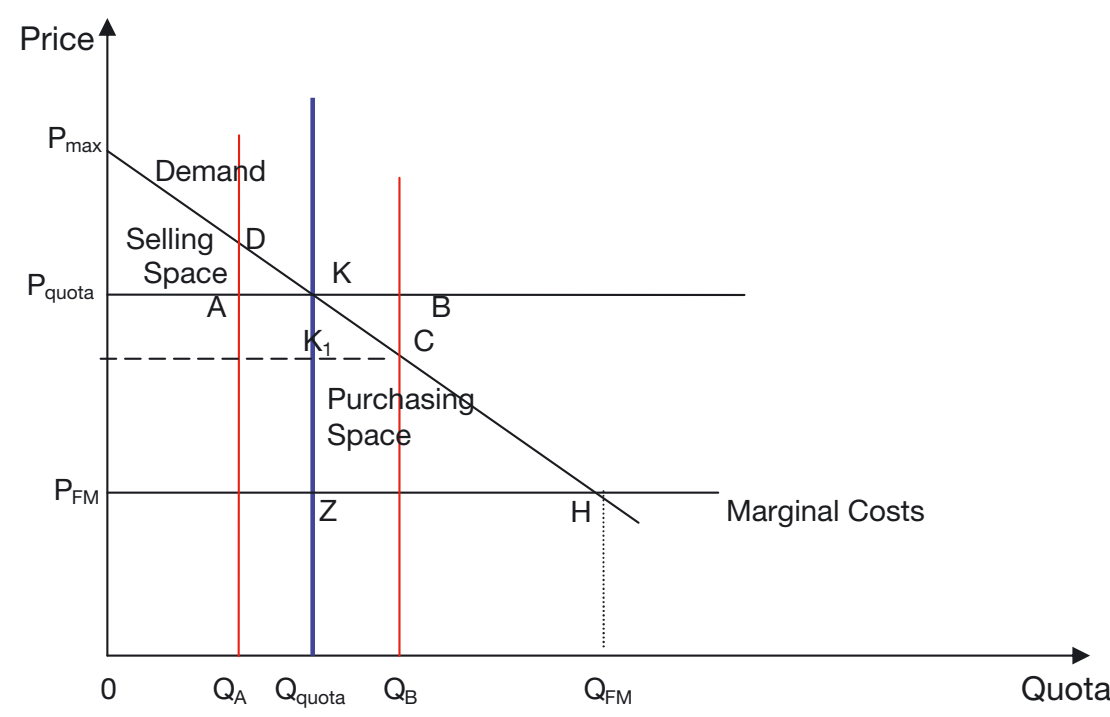

Fig. 1. Hypothetical allocation of quotas and pricing, showing 2 different equilibria related to different orgnizations of trade and pricing in a whale quota market (see 'Trade phase: organization and market structure'). $y$-axis: the price of quotas; $x$-axis: the quantity of quotas; $Q_{\text {quota }}$ : pre-trade allocation of quota; $\mathrm{Q}_{\mathrm{A}}, \mathrm{Q}_{\mathrm{B}}$ : minimum and maximum quota trade caps in a regulated system; $Q_{\mathrm{FM}}$ : total amount of quota that can be traded in a system characterized by free market dynamics; $\mathrm{P}_{\text {quota }}$ : price of quota in a regulated system; $\mathrm{P}_{\max }$ : maximum feasible price of quota in a situation where very few quotas (a number close to $\varepsilon$ ) are traded - important in delimiting the selling space; $\mathrm{P}_{\mathrm{FM}}$ : minimum feasible price of quotas where trade is characterised by free market dynamics; points $\mathrm{K}, \mathrm{H}, \mathrm{Z}$ and points $\mathrm{K}, \mathrm{P}_{\max }, \mathrm{P}_{\text {quota }}$ define the purchasing and selling space in a free market, respectively; points $K, K_{1}, C$ and points $A, D, K$ define the purchasing and selling space in a regulated system, respectively

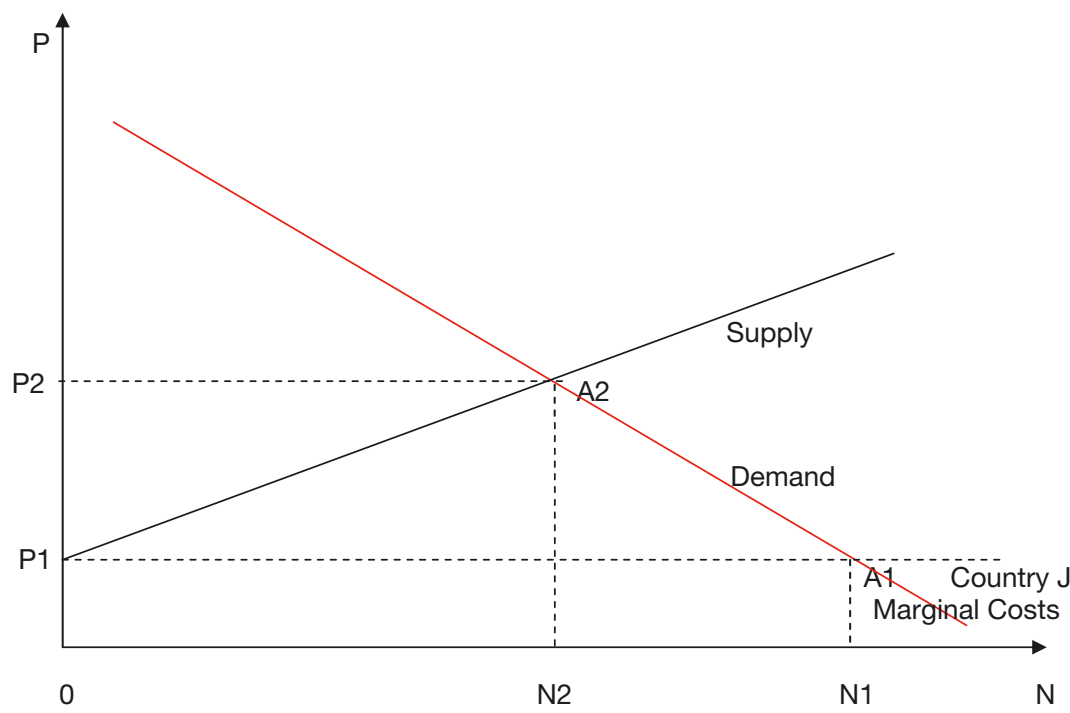

Fig. 2. Hypothetical trade of quotas, showing the trade equilibria under 2 different market structures (competition and monopsony). Different equilibria are summarized (see 'Trade phase: organization and market structure'). $x$-axis: quotas; $y$-axis: price; A1: equilibrium achieved when when trade occurs in a competitive market; N1: amount of quotas traded at price P1 (in microeconomics theory the supply curve equals marginal costs in the short run); A2: equilibrium achieved when trade occurs in a monopsonistic market; N2: amount of quotas traded at price P2 selling and purchasing spaces gets smaller (triangles A-D-K and $\mathrm{K}-$ $\mathrm{K}_{1}-\mathrm{C}$ respectively), and trade is limited by the regulatory authority. However, given potentials for extra trade, this may encourage sellers and buyers to overcome the caps and, therefore, this system requires a strong monitoring apparatus.

Market structure where trade occurs

With respect to the second issue, we focus on exploring the trade dynamics and show the trade equilibria under 2 different market structures (competition and monopsony). Different equilibria are summarized in Fig. 2. If we aggregate all of the 'representative' quota traders and consider an aggregate demand for quotas, we must take into consideration in the analysis important empirical evidence. The starting trade conditions can be equal; however, the trading game will take place in a scenario where the players have different bargaining power and budget constraints. For instance, even if quotas can be purchased by everyone, in reality, there are 3 main whaling countries, 1 of which is by far the biggest demander of quotas. $\stackrel{4}{ }$ In contrast, the structure of the whale-watching market is much less concentrated. This means that 'a larger number' of 'smaller' firms is operating in the sector and producing revenues. Within such a market structure, individual whale-watching firms have lower bargaining power, and the coordina-

${ }^{4}$ At the time of writing there are 3 major whaling countries: Japan, which operates all over the global ocean; Norway, which is now showing signs of declining whaling effort; and Iceland, which resumed whaling a few years ago, with only 1 industrial operator, although whale meat (destined for Japanese consumers) is being held in freezers (see the Norwegian Fisheries Directorate's website: www.fiskeridir.no/fiske-ogfangst/hoeringer/2012/deltakelsen-stuper) 
tion of actions for quota purchasing could be very costly.

For this reason, the analogy of Costello et al. (2012) with the carbon quota market is not appropriate, since all countries produce and pollute. Even the poorest countries, living on subsistence agricultural activities, produce phosphates and other polluting substances. $\frac{\mathbf{5}}{}$ For whaling, the case is much different as not all countries conduct whaling. Therefore, following the theory, we can assume that the most active whaling country, that we denote as Country $\mathrm{J}$, is a monopsonist, i.e. the only buyer of quotas. Economic theory, if well applied, has strong prediction capabilities, and we can show the following, as described in Fig. 4.

In a competitive market, an exchange of quotas occurs at point A2, where demand and supply for the good (quota) meet. An amount N2 of quotas is exchanged at price P2. However, monopsonist Country $\mathrm{J}$ enjoys bargaining power, since it is the only country buying the quotas, and it can renegotiate the price at least until the point where demand equals its marginal costs (A1); after that point, Country J would face losses. Therefore, the monopsonist will buy more quotas (N1) at price P1. In this case, fixing caps for quota trade, as suggested in the previous paragraph, may help to diminish the monopsonistic power of the largest demander of quotas. In this case, whales would be harvested at the agreed sustainable level.

\section{DISCUSSION AND CONCLUDING REMARKS}

We can summarize the findings of our analysis in 2 main points: (1) the choice of the quota pre-trade value, number and allocation mechanism will have different impacts on the way trade will occur; (2) the definition of the rules of trade and the market struc-

${ }^{5}$ The proposal by Costello et al. (2012) of the quota market system seems to be an idea taken from the environmental economics literature and applied to the whaling market without adapting to the current issue. The authors cited the carbon market trading quota as a successful example. However, this is an inappropriate reference to that experience. All countries pollute when performing economic activities (even very poor communities who perform 'slash-and-burn' activities in the forest produce nitrous oxide emissions). Therefore, attributing quotas to all countries and allowing those countries that pollute more to purchase from those who pollute less is a realistic way to minimize a public bad (negative externality), viz. global pollution. Global pollution is a negative externality recognized by all countries, because it has a negative impact on sustainability of resources, on economic growth and on public health. For whaling, the case is much different, since worldwide, there are only 3 major whaling countries ture where trade occurs will also determine the final outcome.

The complexity of the analysed issues, which we have paradoxically left technically simple for divulgating reasons, implies the need for further analysis and recognition of caveats. Every selected quota valuation and allocation criterion, and every discussed trade organization scheme requires careful costbenefit analysis that goes beyond the scope of this paper. For instance, suppose that the quota definition will follow the ecological productivity of the marine resource, such that, on an annual basis, stakeholders can buy only the number of whales that are born in the previous year. Suppose that the value of that quota is defined in auctions, according to bidders' reservation price. Suppose also that the conservationists will be able to buy the entire stock of quotas. An economic analysis will also look at the losses of such an allocation and compute the opportunity costs, for instance in terms of foregone revenues from whaling, generated by that particular allocation of quotas. In addition, in their home countries, whalers are not (only) 'bad' whale exterminators but are (also) wealthproducing (as measured by gross domestic product) firms, whose potential shutting down or decrease in business volume and returns will have negative impacts on the sector's economy, generating related social costs that are borne by the whaling country. The paradoxical results of saving whales by pauperizing humans must be carefully anticipated and scrutinized by a technical cost-benefit ad hoc analysis that takes into consideration all possible impacts.

From our economic analysis, we can predict that the 'quota proposal' may also result in the attribution of a subtle 'licence to kill' to the only potential monopsonist that has the highest willingness to buy and to pay for the entire stock of quotas. Costello et al. (2012) considered only one side of the effects of the quota system (the positive effects where environmentalists buy all the quotas and the number of whales caught would tend toward zero). What about the opposite effect? What if the dominant whaling countries buy the entire world quotas and the catch increases with respect to the status quo? What if the quota trading is done opportunistically, or by cheating (economic agents pursue self-interest by definition)? An economist would reply to the latter that there would be the need to create an ad hoc institution/agency to regulate the 'sustainable quota allocation'. Then, the question would become 'What about transaction/regulating costs of the creation of a brand new quota market, (probably) a regulatory agency and so on?' 
As shown in the previous sections, the way quota number, value and allocation are defined and the way quota trade is organized can have very different impacts on the conservation of whales. Purchasers have different bargaining power and budget constraints; whales have different economic productivity in different economic sectors, and those who derive high profits from the whales will attempt to continue to do so, as much as they can. The idea that conservationists will buy the quotas must be verified empirically. The powerful, albeit abused, economic concept of 'willingness-to-pay' is simply a monetary measure of utility. Only those who will pass the test of evidence and actually purchase the quotas, despite individual budget constraints, will reveal a preference for whales. Economic foundations lie in the management of scarcity, a very concrete activity not well suited to theoretically support, as a discipline, ideological battles. Without the proper quota cap, and a stringent (probably elusive and very costly) monitoring of the trade, whalers might be authorized by the system to hunt the whales to extinction. From this perspective, the maximum allowable quota, determined (but not only) by sustainability criteria as investigated in 'Quota system for whales' as an organization alternative, will only work under stringent monitoring and control activities.

Another critical point refers to the economic cost of maintaining the quota system. First, we consider the costs of creating and implementing a world financial quota market involving 'whaling and non-whaling nations' (Costello et al. 2012, p. 140), when the empirical evidence shows that trade mostly involves 3 countries even though other nations may be willing to participate in the trade.

No less important is the point referring to the 'monitoring' of the governance design. Who controls and monitors that the quota allocations are respected? If countries today do not respect the IWC moratoria, who guarantees that they will respect the quota market and not overfish, despite the quota which they were allocated and which they bought? What are the incentives to respect the pacts? What are the punishments to those who breach the pacts? Who will provide control? The IWC, who assigns the quota? And again, Who controls the controllers? What if the quota trading is done opportunistically? And who will pay for those (presumably high) transaction costs that the proposal implementation might generate? Finally, without stringent control, a regulated system (with maximum allowable quota) might generate parallel illegal markets of quotas, viz. arbitrage by those who will buy in order to sell at an increased price to the whaling countries in illegal markets.

One final point: despite all of its limitations and gaps, the quota proposal is grounded in a serious attempt to solve a real problem, caused by few economic agents that extract rents, generating the depletion of the stock of a very important marine resource. Economic analysis and learning-by-doing might eventually help in designing the most proper quota pretrade and trade architectural structure. Alternative solutions are not easy to suggest. Designing incentives that spur agents to give up whaling and opt for more ecologically sustainable activities linked to the economic exploitation of whales, like whale watching, implies entering the realm of individual, social and cultural preference structures and completely restructuring them. This is not an impossible task, but it is a task that requires a massive investment in marine ecology literacy and focused educational campaigns. And that requires time. Whale watching is ecologically sustainable and, to the extent possible, meets the requirements of the industry and expectations of the wider community. Differently from the whaling sector, where demand is mostly domestic, potential demand for whale watching is also international. Supply can be provided by both subsistence and commercial whaling countries, but also by countries where whales migrate to or through, or where there are whale sanctuaries, and complement tourism/ecotourism activities. Furthermore, if all countries that develop the whale-watching sector will control that whales are not over-harvested by commercial whaling countries, this might eventually spur the latter to switch to whale watching as well. If populations of whales are to be conserved out of respect for ecological equilibria and for the benefit of future generations, current generations must be taught, within the boundaries of respect for cultural traditions, to appreciate a whale swimming in the open sea more than the same whale served in a dish.

Acknowledgements. We thank Rashid Sumaila, Andrea Ghermandi, Frederic Briand, Maria Loureiro and John Gowdy for stimulating discussions. In addition, we thank 3 anonymous referees for valuable critical points that helped to substantially improve the previous version of this manuscript.

\section{LITERATURE CITED}

Cisneros-Montemayor AM, Sumaila UR, Kaschner K, Pauly D (2010) The global potential for whale watching. Mar Policy 34:1273-1278

Clark C (1973) Profit maximization and the extinction of ani- 
mal species. J Polit Econ 81:950-961

Costello C, Gerber LR, Gaines S (2012) A market approach to saving the whales. Nature 481:139-140

Ghermandi A, Nunes PALD (2013) The economics of marine ecosystems: reconciling use and conservation of coastal and marine systems and the underlying natural capital. Environ Resour Econ 56:459-465

O'Connor S, Campbell R, Cortez H, Knowles T (2009) Whale watching worldwide: tourism numbers, expenditures and expanding economic benefits. Special report. International Fund for Animal Welfare, Yarmouth, MA

Schipper J, Chanson JS, Chiozza F, Cox NA and others (2008) The status of the world's land and marine mammals: diversity, threat, and knowledge. Science 322: 225-230

Smith M, Asche F, Bennear LS, Havice E, Read AJ, Squires D (2014) Will a catch share for whales improve social welfare? Ecol Appl 24:15-23

Appendix. Glossary

\author{
Economic policy instrument \\ An economic policy instrument is an incentive (i.e. a subsidy) or a disincentive (i.e a tax) that the policy maker uses in \\ order to design and implement public policies
}

\title{
Free rider
}

In economics, a free rider is a consumer of a public good that does not pay for the good. Since the public good is nonexcludable and non-rival in consumption, the free rider will benefit from the good without bearing the costs of the provision of the public good

\section{Impure public good}

In economic theory: (a) A pure public good is a good that is both nonrivalrous and nonexcludable in consumption.

(b) A pure private good is a good that is both excludable and fully rivalrous in consumption.

(c) An impure public good is a good that is nonexcludable and partially rivalrous, like, for instance, a park or a highway

\section{Marginal revenues}

Marginal revenues are the additional revenues generated by the sale of one additional unit of product. Marginal costs are the additional costs generated by the production of one additional unit of product

\section{Monopsony}

Monopsony is a market structure characterized by only one buyer and many sellers

\section{Opportunity costs}

The value of the best alternative choice that is forgone, in a situation in which a choice needs to be made between several mutually exclusive alternatives, given limited resources

\section{Positive externality}

A positive externality is an economic benefit

\section{Revealed preferences}

The preferences of consumers that can be revealed by their purchasing habits

\section{Scarcity rent}

Scarcity rents are surplus generated by the exploitation of scarce resources

\section{Stylized facts}

A tool of professional economists. Stylized facts represent a broad synthesis of evidence. A stylized fact is a simplified presentation of an empirical finding or an empirical regularity 